most persistent cases will take. Corneal refractive procedures looked at in this light can never be truly predictable in the same sense as the term would be used in more straightforward surgical circumstances.

Light is showing at the end of this tunnel. As our experience with PRK progresses and the software and hardware available are progressively refined, so we are starting to see increasing numbers of patients and proportions of patient populations falling into the category of both surgical success and good patient satisfaction. ${ }^{78}$ In our own refractive service, the quality of results between our phase III and phase IV has been dramatic. The 1 year results for patients with up to 8 dioptres of preoperative myopia are now as good as anything that can be achieved by laser intrastromal keratomileusis (LASIK), and, of course, with a very much simpler technique. Corneal opacity as a worrying iatrogenic factor is steadily subsiding and, hopefully, with it will disappear the problems of irregular astigmatism, central islands, and lines of lost BCVA. When such pleasing improvements can be reported following procedures for hypermetropia and high myopia, we will be able to feel more comfortable about the risks to vision. Meanwhile, it is my contention that the expression of predictability should not be aired in a clinical context where patients are likely to misunderstand the expression as being positively encouraging, irrespective of whatever figures are put up beside it.

ARTHUR STEELE

62 Wimpole Street, London W1M 7DE

1 Koch DD, Kohnen T. McDonnell PJ, Menefee RF, Berry MJ. Hyperopia correction by noncontact holmium:YAG laser thermal keratoplasty. Ophthalmology 1996;103:1525-36.

2 John ME, Martines E, Cvintal T. Photorefractive keratectomy for residual myopia after radial keratotomy. F Cataract Refract Surg 1996;22:901-5.

3 Waring GO, Casebeer JC, Dru RM. One-year results of a prospective multicenter study of the Casebeer system of refractive keratotomy. Ophthalmolticenter study of the Cas $1996 ; 103: 1337-4$.

4 Werblin TP, Stafford GM. Three year results of refractive keratotomy using the Casebeer system. F Cataract Refract Surg 1996;22:1023-9.

5 Tabin GC, Alpins N, Aldred GF, McCarty CA, Taylor HR. Astigmatic change 1 year after excimer laser treatment of myopia and myopic astigmatism. F Cataract Refract Surg 1996;22:924-30.

6 Butuner Z, Elliott DB, Gimbel HV, Slimmon S. Visual function one year after excimer laser photorefractive keratectomy. I Refract Corneal Surg 1994;10:625-30.

7 Visx US Multicenter Trial Data submitted to the FDA, October 1995. VISX Excimer Laser System. Photorefractive keratectomy (PRK). PMA P930016.

8 Moorfields Excimer Laser Data: Model C 'Star' Laser. US FDA PMA P930016/S003/A3.

\title{
A British ophthalmological surveillance unit
}

There are a number of rare ophthalmological conditions that individual clinicians may only see every 1 to 2 years. By themselves, these conditions contribute very little to national visual morbidity but are often of great inherent interest to the ophthalmological community as a whole for a number of reasons.

Firstly, it is evident that certain rare diseases provide fundamental models that would help in the understanding of the pathogenesis of other commoner disorders. In the field of uveitis, for instance, comprehension of the mechanisms that underlie sympathetic ophthalmia would not only improve the management of this disease in those rare patients that contract it, but also might throw light on the pathogenesis of many disorders that result in intraocular inflammation from whatever cause. Similarly, the rapid identification of patient pedigrees in uncommon genetic disorders and the application of modern molecular genetic techniques to these rare cases could have a major impact in the field of prenatal screening and, ultimately, in their possible cure. Secondly, the ability to identify rare complications of common diseases or procedures may be of direct relevance to the ophthalmological community as a whole: the changing incidence of life threatening reactions to different techniques of ocular anaesthesia or the prevalence of systemic complications to the injection of fluorescein dye are cases in point. The size of the problem needs to be known in order to advise on optimum clinical practice-for example, the necessity for full time anaesthetic support, etc. Thirdly, the collection of rare cases for cohort studies either for the characterisation of the natural history of the disorder (such as the outcome in patients with treated retinopathy of prematurity) or for the accumulation of sufficient cases for meaningful prospective therapeutic trials (for example, in fungal keratitis) would be a major benefit.

Finally, and most importantly, the collection of epidemiological data on the incidence and prevalence of rare diseases (or changes in these factors) would have important implications for public health. This aspect is possible since ophthalmologists are the only members of the medical profession involved in the management of eye disease. The impact on public health is exemplified by the two infectious diseases, toxoplasmosis and toxocariasis. These diseases have emerged as public health problems, not because their epidemiology is changing, but because of increased public awareness of their impact on the health of both children and adults, in particular their potential to cause blindness. In the case of toxoplasmosis this has revolved around campaigns to promote a nationwide screening programme of pregnant women for congenital toxoplasmosis and, in the case of toxocariasis, campaigns to promote responsible dog ownership and the exclusion of dogs from public parks. In both instances, statements about the size of the problem are not based on fact and have often been embellished in order to stimulate public and political interest. The figures quoted tend to be alarming and consequently emotive, and are usually derived from old ad hoc studies whose results have been unreasonably extrapolated. Further recent examples to illustrate these public health issues might be the change in incidence of acanthamoeba keratitis with disposable contact lens wear, or the possible association of anophthalmia with insecticide usage.

Against this background there is clearly a need for a specialised ophthalmological surveillance unit. At present, investigators interested in identifying these rare diseases nationally must rely on passive, retrospective reporting resulting from expensive and extensive mailshots often with poorly validated, cumbersome questionnaires. Since remembering individual cases is rarely good the result is usually a poor response. A suitable model for acquiring the necessary information would be by active case ascertainment of the disease of interest. In this system individual ophthalmologists would receive a reporting card every month on which they would tick whether they had had a 
case of the relevant condition or not. Collation of these data would enable interested research groups to target the reporting clinician with a more detailed questionnaire (and also identify cases of duplicate reporting) with the added advantage of reducing the overall workload of reporting clinicians. This common research resource would be administered by a steering committee that would advise on study and questionnaire design as well as maintaining standards so that meaningful statements about the epidemiology of the condition of interest could be made.

This model of active case ascertainment has been in use by the British Paediatric Association since 1986 and has facilitated a large number of studies of rare childhood disorders. ${ }^{1}$ It currently achieves a response rate of more than $90 \%$ and has led to the formation of similar units in other countries of the world as well as in the disciplines of neurology, ${ }^{2}$ orthopaedics, and dermatology. It is highly valued by participating clinicians as a research tool to which they all contribute and which they in turn can use if they wish to study a disorder of sufficient rarity that ascertainment on a national basis is required. The Royal College of Ophthalmologists in conjunction with the Iris Fund for the Prevention of Blindness has now established such a unit in the United Kingdom; not only will this provide a valuable service to the ophthalmological community as a whole, but it will also enhance our specialty's role in research, public health, and education.

M R STANFORD

on behalf of the British Ophthalmological

Surveillance Unit Steering Committee,

St Thomas's Hospital, London

1 British Paediatric Surveillance Unit. Lancet 1992;340:845.

2 Cockerell OC, Gupta S, Catchpole M, Sander JW, Shorvan SD. The British Neurological Surveillance Unit: a nationwide scheme for the ascertainment of rare neurological disorders. Neuroepidemiology 1995;14:182-7. 